\title{
PYOCINE TYPING OF MUCOID STRAINS OF PSEUDOMONAS AERUGINOSA ISOLATED FROM CHILDREN WITH CYSTIC FIBROSIS
}

\author{
Rosamund J. Williams and J. R. W. Govan \\ Bacteriology Department, University of Edinburgh Medical School, \\ Teviot Place, Edinburgh, EH8 9 AG
}

CHILDREN suffering from cystic fibrosis (CF) are very susceptible to pulmonary infections especially with Staphylococcus aureus and Pseudomonas aeruginosa (Huang, Van Loon and Sheng, 1961; Iacocca, Sibinga and Barbero, 1963), and strains of the latter organism isolated from such infections are unusual in that many of them form very mucoid colonies on solid media (Doggett, 1969; Doggett, Harrison and Carter, 1971). Mucoid and non-mucoid strains of $\boldsymbol{P}$. aeruginosa are often found in the same specimen, and as the infection progresses the mucoid strain usually comes to predominate with a concomitant decline in the condition of the patient (Doggett et al., 1966). The relationship between mucoid and non-mucoid colonial forms has not been firmly established, but some workers believe them to be variants of the same strain (Feigelson and Pecau, 1966). Characterisation of the mucoid strains is difficult, but Diaz, Mosovich and Neter (1970) reported that, when serological typing was possible, mucoid and non-mucoid isolates from the same specimen belonged to the same serotype. Other authors have suggested that the mucoid organism is another and superinfecting strain that finds the environment of the cystic fibrotic lung particularly suited to its growth (Doggett, Harrison and Wallis, 1964).

This paper reports a preliminary investigation in which pyocine typing (Gillies and Govan, 1966; Govan and Gillies, 1969) was used to examine the relationship between mucoid and non-mucoid strains.

\section{MATERIALS AND METHODS}

Isolation of strains. Sputum specimens were obtained from patients attending the CF Clinic at the Royal Hospital for Sick Children, Edinburgh, or strains of $\boldsymbol{P}$. aeruginosa isolated from the same patients were sent to us from the Central Microbiological Laboratories, Edinburgh. Specimens were plated on horse-blood agar, MacConkey's medium and cetrimide agar ( 0.03 per cent. cetrimide in nutrient agar), and incubated aerobically at $37^{\circ} \mathrm{C}$ for $18 \mathrm{hr}$. Colonies from cetrimide plates were picked and their identification confirmed as $P$. aeruginosa by the oxidase test (Kovács, 1956) and by their pigment production on King's media (King, Ward and Raney, 1954). The MacConkey plates were also examined for $\boldsymbol{P}$. aeruginosa, particularly when there was little or no growth on the cetrimide agar.

Pyocine typing. Strains were typed within a few days of isolation, and sub-cultures were stored on nutrient agar slopes in screw-capped bottles at room temperature $\left(c .22^{\circ} \mathrm{C}\right)$ in the dark. The method of pyocine typing described by Gillies and Govan was used. In addition to the tryptone soya blood agar medium used by these authors, various other media were tested-a minimal medium (Clarkson and Meadow, 1971) incorporating 0.1 per cent. of glucose, sodium glutamate or sodium succinate as sole carbon source, and also a very simple medium containing L-asparagine (Georgia and Poe, 1931).

Production of pyocines in liquid culture. A $100-\mathrm{ml}$ volume of tryptone soya broth in a 2-1 flask was inoculated with $2 \mathrm{ml}$ of an overnight broth culture of the strain to be examined and then incubated in an orbital incubator at $37^{\circ} \mathrm{C}$ and 80 r.p.m. for $4 \mathrm{hr}$. Mitomycin C (1.5 $\mu \mathrm{g}$ per $\mathrm{ml}$ final concentration) was added to some cultures as an inducing agent. For 
both induced and uninduced cultures, incubation was continued for a further $4 \mathrm{hr}$ and then the lysates were centrifuged to remove the cells; the supernates containing the pyocines were sterilised with 5 per cent. $(\mathrm{v} / \mathrm{v})$ chloroform for $15 \mathrm{~min}$. and the chloroform was then allowed to settle and the supernates were decanted.

Detection of pyocine in liquid cultures. Four-hour broth cultures of the indicator strains, nos. 1-8 (Gillies and Govan), were used to make lawns on nutrient agar plates containing $9 \mathrm{ml}$ of agar in plastic petri dishes (diameter $9 \mathrm{~cm}$ ). Doubling dilutions of the pyocine extract were prepared in sterile physiological saline and $0.02-\mathrm{ml}$ drops of each dilution were spotted on to the well-dried indicator lawns. The drops were allowed to dry and the plates were incubated aerobically at $37^{\circ} \mathrm{C}$ overnight. The presence of pyocine activity was indicated by zones of inhibition on the indicator lawns.

Detection of bacteriophage. When bacteriophages that attacked the indicator strains were present in the pyocine extracts, they were recognised on the pyocine-titration plates by their plaque-forming ability.

TABLE

Pyocine typing of mucoid and non-mucoid P. aeruginosa strains isolated from the sputum of children with cystic fibrosis

\begin{tabular}{|c|c|c|c|c|c|c|}
\hline \multirow{3}{*}{$\begin{array}{l}\text { Patient } \\
\text { number }\end{array}$} & \multicolumn{6}{|c|}{ Character of $P$. aeruginosa } \\
\hline & \multicolumn{2}{|c|}{ Colony form } & \multicolumn{2}{|c|}{ Pyocine type on TSBA* } & \multicolumn{2}{|c|}{$\begin{array}{l}\text { Pyocine type after } \\
\text { induction in broth }\end{array}$} \\
\hline & Mucoid & Non-mucoid & Mucoid & Non-mucoid & Mucoid & Non-mucoid \\
\hline $\begin{array}{r}1 \\
2 \\
6 \\
11 \\
33 \\
34 \\
5 \\
10 \\
42\end{array}$ & $\begin{array}{l}+ \\
+ \\
+ \\
+ \\
+ \\
+ \\
+ \\
+ \\
+\end{array}$ & $\begin{array}{l}+ \\
+ \\
+ \\
+ \\
+ \\
+ \\
- \\
-\end{array}$ & $\begin{array}{c}1 / \mathrm{c} \\
\mathbf{u} / \mathbf{t} \\
\mathbf{u} / \mathbf{t} \\
(3) \dagger \\
\mathbf{u} / \mathbf{t} \\
(1 / \mathrm{h}) \dagger \\
(29) \dagger \\
\mathbf{u} / \mathbf{t} \\
\mathbf{u} / \mathbf{t}\end{array}$ & $\begin{array}{c}1 / \mathrm{c} \\
13 \\
3 \\
3 \\
1 / \mathrm{h} \\
1 / \mathrm{h} \\
= \\
-\end{array}$ & $\begin{array}{c}1 / \mathrm{c} \\
13 \\
3 \\
3 \\
1 / \mathrm{h} \\
1 / \mathrm{h} \\
29 \\
1 / \mathrm{b} \\
5\end{array}$ & $\begin{array}{c}1 / \mathrm{c} \\
13 \\
3 \\
3 \\
1 / \mathrm{h} \\
1 / \mathrm{h} \\
= \\
=\end{array}$ \\
\hline
\end{tabular}

$+=$ Strain isolated; $-=$ strain not isolated; $u / t=$ untypable.

* TSBA = Tryptone Soya Agar with 5 per cent. horse blood.

$\dagger$ Indicator strains weakly inhibited.

\section{Results}

Pseudomonas aeruginosa was isolated from the sputum of nine of the 25 patients examined and from six of these nine specimens mucoid and non-mucoid strains were isolated simultaneously. The non-mucoid strains were all typable by the standard typing technique, whereas five of the six mucoid strains were untypable or gave very indistinct patterns (the table).

When the typing method was modified by the use of different growth media, all the strains grew on each of the substrates tested but there was little reduction in the amount of slime produced by the mucoid strains. When sodium succinate was used as the sole carbon source, it was possible to show some inhibition of the indicator strains by the mucoid strains but the results were neither clear nor reproducible.

Growth of mucoid strains in broth culture at $32^{\circ} \mathrm{C}$ resulted in the spontaneous production of pyocines in low concentration; higher concentrations and clearer results were obtained when such broth cultures were induced with Mitomycin C. Identical inhibition patterns corresponding to those of recognised pyocine types were obtained with induced and un- 
induced cultures. In each of the six patients, the mucoid and non-mucoid strains isolated from the same specimen were found to belong to the same pyocine type (the table). When replicate specimens were obtained (2-9 specimens per patient), five of the six patients were found to carry the same pyocine type of $P$. aeruginosa for 2-8 $\mathrm{mth}$.

In addition, three patients produced only mucoid strains of $P$. aeruginosa, and when these strains were characterised by extraction and assay of their pyocines, they were found to belong to recognised pyocine types (the table).

To confirm that the typing of strains after induction with Mitomycin $\mathrm{C}$ did not inevitably result in pyocine production, attempts were made to induce pyocine production in 12 wild strains of $P$. aeruginosa that were untypable by the standard technique. No inhibition of the indicator strains due to pyocine activity was observed with any of these strains.

Lysogeny is very common in $P$. aeruginosa (Holloway, 1969), and bacteriophages attacking the indicator strains were found in many of the cystic fibrosis strains examined. The similar range of activity of the phages from mucoid and non-mucoid strains from the same patient was taken as further evidence that these strains were related. It was possible to distinguish between inhibition due to pyocine and due to phage at higher dilutions of the extract where distinct phage plaques were observable, in contrast to the gradual thinning of the indicator lawn due to pyocine inhibition.

\section{DisCussion}

The origin of the mucoid variant of $P$. aeruginosa in patients with $\mathrm{CF}$ has been a subject of controversy, and although most workers agree that the mucoid and non-mucoid colonial forms are variants of the same strain, this has not been conclusively demonstrated (Feigelson and Pecau, 1966); the present study provides evidence that they are.

Strains of $\boldsymbol{P}$. aeruginosa may be typed serologically, by their sensitivity to bacteriophages and by pyocine typing. The first two of these methods may be used in combination and depend on properties of the outer surface of the cell, respectively of the $O$ antigens and of the receptor sites for bacteriophages. Mucoid strains are not easily typed by these methods because of the mucus surrounding the cell surface. Pyocine typing depends on the release of pyocines from the cell into the surrounding medium and the subsequent action of these pyocines on the indicator strains.

Gillies and Govan (1966) found that 90-95 per cent. of $P$. aeruginosa strains were typable by their technique. In this study the non-mucoid strains of CF origin were all typable, but only a small number of the mucoid isolates could be typed by the standard method. Rosenstein and Drachman (1968) were able to type 79 per cent. of $P$. aeruginosa strains from CF patients, but they did not state the number of mucoid strains examined. Schwarzmann and Boring (1971) suggested that mucoid strains may be apyocinogenic. We consider it more likely that the mucoid strains produce pyocines and that these are prevented from diffusing into the medium by the mucus surrounding the cells. Some of the mucoid strains in this series were found to be typable by the standard method, and this may be related to the size and nature of the pyocines produced, to the amount of slime elaborated by the organisms or to both. When simple synthetic media were used for typing, some pyocineinhibition patterns were observed, suggesting that the mucoid strains were not apyocinogenic. In shaken broth cultures of mucoid strains the slime was dispersed and the pyocines produced by the cells were released into the medium. The presence of the pyocines was demonstrated by the assay of the culture supernates against the standard indicator strains and the inhibition patterns produced could be recognised as those of standard pyocine types.

\section{SUMMARY}

The relationship between mucoid and non-mucoid strains of Pseudomonas aeruginosa isolated from the sputum of children with cystic fibrosis was investigated by typing the strains by pyocine production. The mucoid strains were usually untypable by the standard technique, but extraction and assay of the pyocines produced in liquid cultures showed 
that the strains belonged to recognised pyocine types. When mucoid and non-mucoid strains occurred simultaneously, they were of the same pyocine type; it is suggested that they are variants of the same strain.

We wish to thank Dr W. M. McCrae and the staff of the Royal Hospital for Sick Children, Edinburgh for their co-operation, $\mathrm{Dr} \mathrm{K}$. C. Watson for providing strains of $\boldsymbol{P}$. aeruginosa, and Dr R. R. Gillies for his advice. This work has been carried out with the aid of a grant from the Medical Research Council (M.R.C. Grant G 971/121/B) held by Dr R. R. Gillies, Department of Bacteriology, University of Edinburgh.

\section{REFERENCES}

Clarkson, Carolyn E., and Meadow, Pauline M. 1971. Diaminopimelic acid and lysine auxotrophs of Pseudomonas aeruginosa 8602. J. Gen. Microbiol., 66, 161.

Diaz, F., Mosovich, L. L., AND Neter, E. 1970. Serogroups of Pseudomonas aeruginosa and the immune response of patients with cystic fibrosis. J. Infect. Dis., 121, 269.

Doggert, R. G. 1969. Incidence of mucoid Pseudomonas aeruginosa from clinical sources. Appl. Microbiol., 18, 936.

Doggett, R. G., Harrison, G. M., and Carter, R. E., JR 1971. Mucoid Pseudomonas aeruginosa in patients with chronic illnesses. Lancet, 1, 236.

Doggett, R. G., Harrison, G. M., Stillwell, R. N., and Wallis, E. S. 1966. An atypical Pseudomonas aeruginosa associated with cystic fibrosis of the pancreas. J. Pediat., 68, 215.

Doggett, R. G., Harrison, G. M., AND Wallis, E. S. 1964. Comparison of some properties of Pseudomonas aeruginosa isolated from infections in persons with and without cystic fibrosis. J. Bact., 87, 427.

Feigelson, J., AND PeCAU, Y. 1966. In Proceedings of 4th international conference on cystic fibrosis of the pancreas (mucoviscidosis). Edited by E. Rossi and E. Stoll, Basel, p. 214.

Georgia, F. R., AND PoE, C. F. 1931. Study of bacterial fluorescence in various media. J. Bact., 22, 349.

Gillies, R. R., AND Govan, J. R. W. 1966. Typing of Pseudomonas pyocyanea by pyocine production. J. Path. Bact., 91, 339.

Govan, J. R. W., AND Gillies, R. R. 1969. Further studies in the pyocine typing of Pseudomonas pyocyanea. J. Med. Microbiol., 2, 17.

Holloway, B. W. 1969. Genetics of Pseudomonas. Bact. Rev., 33, 419.

Huang, Nancy N., Loon, Emily L. van, and Sheng, K. T. 1961. The flora of the respiratory tract of patients with cystic fibrosis of the pancreas. J. Pediat., 59, 512.

IACOcCA, V. F., Sibinga, M. S., AND BARbero, G. J. 1963. Respiratory tract bacteriology in cystic fibrosis. Amer. J. Dis. Child., 106, 315.

King, Elizabeth O., Ward, Martha K., and Raney, D. E. 1954 . Two simple media for the demonstration of pyocyanin and fluorescin. J. Lab. Clin. Med., 44, 301.

Kovács, N. 1956. Identification of Pseudomonas pyocyanea by the oxidase reaction. Nature, Lond., 178, 703.

Rosenstein, Beryl J., And Drachman, R. H. 1968. Pyocine production by Pseudomonas aeruginosa in patients with cystic fibrosis. Bact. Proc., 101.

Schwarzmann, S., AND BorIng, J. R. 1971. Antiphagocytic effect of slime from a mucoid strain of Pseudomonas aeruginosa. Infect. Immun., 3, 762. 